\title{
Cladding-pumped L-band phosphosilicate erbium-ytterbium co-doped fiber amplifier
}

\author{
C. Codemard ${ }^{1}$, D. B. S. Soh ${ }^{1}$, K. Ylä-Jarkko ${ }^{2}$, J. K. Sahu ${ }^{1,2}$, M. Laroche ${ }^{1}$, and J. Nilsson ${ }^{1,2}$ \\ ${ }^{1}$ Optoelectronics Research Center, SO17 1BJ, Southampton, United Kingdom \\ 44(0) 2380593143 cac@orc.soton.ac.uk \\ ${ }^{2}$ Southampton Photonics, Phi House, SO16 7NS, Southampton, United Kingdom
}

\begin{abstract}
We report a cladding-pumped broadband L-band amplifier based on a phosphosilicate erbium ytterbium doped fiber. A gain of more than $20 \mathrm{~dB}$ has been achieved from 1553 to 1620 $\mathrm{nm}$ in a $5 \mathrm{~m}$ long fiber in a double-pass amplifier configuration. (C)2003 Optical Society of America

OCIS codes: (060.2410) Fibers, erbium; (060.2320) Fiber optics amplifiers and osc illators
\end{abstract}

\section{Introduction}

The capability of erbium to amplify in the L-band, ranging from $\sim 1570 \mathrm{~nm}$ to $\sim 1610 \mathrm{~nm}$ was recognized early [1]. L-band EDFAs are primarily seen as a complement to C-band EDFAs working in the $1530-1560 \mathrm{~nm}$ wavelength range, to be used only after the bandwidth of the C-band has been exhausted. However, in a head-tohead comparison between L- and C-band EDFAs, L-band EDFAs can be superior in terms of gain bandwidth, with aluminosilicate EDFAs presenting an intrinsically flat L-band gain. Relative disadvantages of L-band EDFAs include a lower efficiency, leading to high pump power requirements, and a low gain per unit length, leading to undesirably long fibers. Higher erbium-concentrations can be used to reduce the fiber length, but then concentrationquenching becomes an issue. This depends strongly on the host glass composition. For example, bismuth oxide glass allows for high L-band gain per unit length in fibers doped with $6500 \mathrm{ppm}$ Er by weight [2]. However, this is a nonsilica glass, presenting considerable challenges in fabrication and handling. Instead, high-silica glasses are often preferred because of their high quality and reliability, and highly developed fabrication methods such as MCVD. To reduce concentration quenching, another rare earth can be incorporated to prevent the Er-ions from clustering. For example, $2700 \mathrm{ppm}$ (wt) Er-concentration was obtained in a germano-aluminosilicate fiber co-doped with lanthanum [3]. Here, the aluminum helps to increase the rare-earth solubility of the host glass. Alternatively, phosphosilicate fibers are known for their good rare earth solubility. Well-established erbium-ytterbium co-doped phosphosilicate fibers are therefore good candidates for L-band EDFAs, in this case with ytterbium to mitigate Erclustering. Our erbium-ytterbium phosphosilicate fiber fabrication process is detailed in ref. [4]. Besides the potential of high gain per unit length in the L-band, they bring two additional important advantages: The gain spectrum is broadened and extends to $1620 \mathrm{~nm}$. Furthermore, the possibility to use indirect pumping and energy transfer from $\mathrm{Yb}$ to Er facilitate high-power pumping schemes, e.g., with $1064 \mathrm{~nm}$ crystal or glass lasers as well as cladding-pumping with high-power multimode diode sources at, e.g., 915, 940, and $975 \mathrm{~nm}$. [5, 6] Especially diode cladding-pumping appears attractive, since this provides for a high pump power at a low cost and lessens the disadvantage of a low efficiency in the L-band. In particular, for $915 \mathrm{~nm}$ and $940 \mathrm{~nm}$ pumping, the absorption spectrum is quite broad so that uncooled diodes can be used. Furthermore, cladding-pumping and ytterbium codoping technology allows for the pump absorption to be controlled independently of the Er-concentration. This way a distributed pumping of the amplifier can be achieved, which is important for L-band operation [7]. By contrast, conventional Yb-free, core-pumped L-band EDFAs suffer from excessive pump absorption, leading to problems with strong ASE [8].

These advantages of L-band erbium-ytterbium fiber amplifiers (EYDFAs) have all been recognized, and an Lband EDFA with a cladding-pumped erbium-ytterbium co-doped fiber (EYDF) booster stage has been presented [9]. However, the gain bandwidth was limited and there was little data on the booster stage. Thus, despite the considerable attractions, the capabilities of cladding-pumped L-band EYDFAs remain largely unexplored.

In this paper, we present a phosphosilicate EYDFA cladding-pumped by a broadstripe $915 \mathrm{~nm}$ laser diode. We find that the properties of erbium-ytterbium co-doped phosphosilicate fibers combine in a remarkable way in cladding-pumped L-band amplifiers, providing good performance, simple design, and low-cost pumping, even with short lengths of fiber. A $5 \mathrm{~m}$ long piece of fiber, fabricated in-house and with $3800 \mathrm{ppm} \mathrm{Er} \mathrm{(wt)} \mathrm{provided} \mathrm{over} 20 \mathrm{~dB}$ of gain from 1553 to $1620 \mathrm{~nm}$ in a double-pass configuration, with up to $23 \mathrm{dBm}$ of saturated output power.

\section{Double-clad Er-Yb co-doped fiber and experimental set-up}

Our double-clad fiber has a $125 \mu \mathrm{m}$ circular inner-cladding with an NA of 0.48 . The core has a $12.5 \mu \mathrm{m}$ diameter with an NA of 0.2. This makes the core multi-moded, but it still allows for robust single-mode operation. The large, high-NA core leads to a strong overlap between the signal and the doped area [10], calculated to $97 \%$ in our case. 
The erbium concentration is $3800 \mathrm{ppm}$ (wt). The core absorption at the peak at $\sim 1536 \mathrm{~nm}$ is $67 \mathrm{~dB} / \mathrm{m}$ while the pump absorption at $915 \mathrm{~nm}$ is $\sim 1 \mathrm{~dB} / \mathrm{m}$ in the inner cladding. The background loss has been measured to be $\sim 17$ $\mathrm{dB} / \mathrm{km}$ at $1300 \mathrm{~nm}$. Erbium emission and absorption cross-sections in the $1550 \mathrm{~nm}$ band were determined using the McCumber and Fuchtbauer-Ladenburg relations (Fig. 1). The emission is significant even beyond $1625 \mathrm{~nm}$, though excited-state absorption is known to limit long-wavelength amplification.

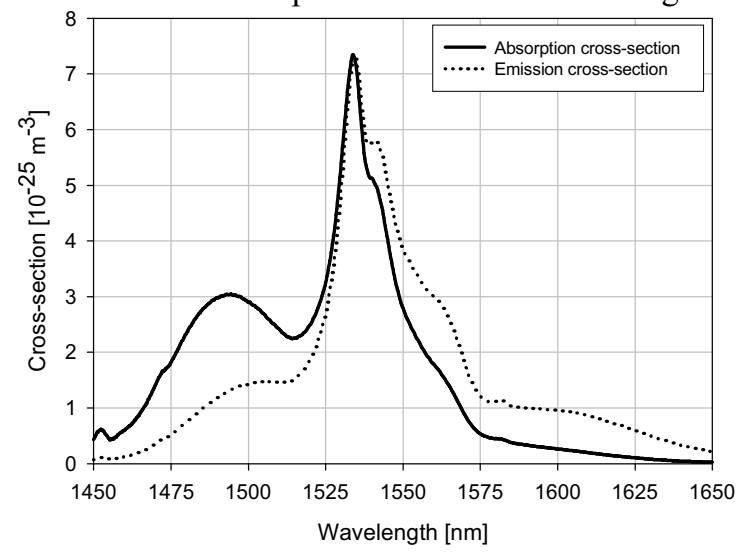

Figure 1: Experimental cross-sections of the erbiumytterbium co-doped fiber.

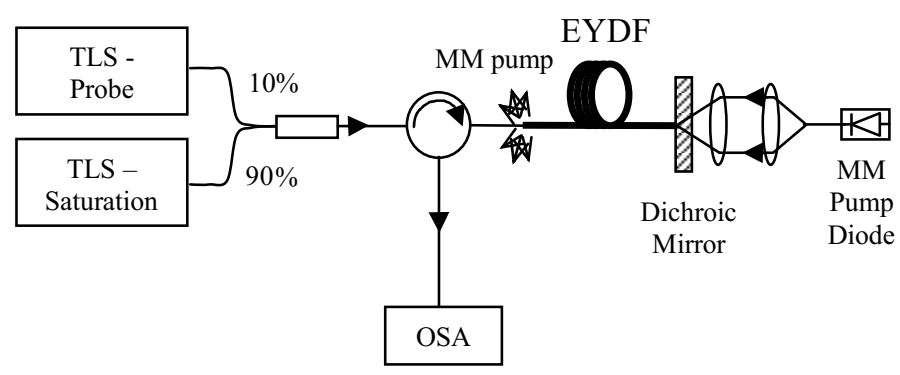

Figure 2: L-band EYDFA experimental set-up.

The EYDF is used in a double-pass amplifier configuration. The experimental set-up is shown in Fig. 2. It consists of a $915 \mathrm{~nm}$ pig-tailed multimode laser diode with $1.9 \mathrm{~W}$ of output power. The pump beam is launched into the doped fiber via a pair of lenses. The double-clad fiber is butted against a dichroic mirror which is highly reflective from $1500 \mathrm{~nm}$ to $1620 \mathrm{~nm}$ and highly transmissive from 900 to $1000 \mathrm{~nm}$. The coupling efficiency is $65 \%$ with 1.25 $\mathrm{W}$ of pump power launched into a $5 \mathrm{~m}$ long doped fiber. The absorbed pump power is $850 \mathrm{~mW}$. The EYDF is spliced to standard single-mode fiber. The multimode pump power leaking through the EYDF is stripped away with an index-matching gel. A circulator is used to launch the input signal and to extract the amplified output signal. The insertion loss of the circulator is $1 \mathrm{~dB}$. A high-power (saturating) and low-power (probe) signal can be simultaneously injected into the EYDFA for measurements of so-called locked-inversion (as well as single-channel) gain spectra under different saturation conditions. The output of the circulator is connected to a calibrated optical spectrum analyzer where the amplified output is measured.

\section{Results}

Figure 3 shows single-channel gain spectra at various input powers. The small-signal gain $(-30 \mathrm{dBm}$ input power) exceeds $20 \mathrm{~dB}$ from 1553 to $1620 \mathrm{~nm}$. Figure 4 shows the WDM gain spectra and noise figure measured with a swept low-power probe under saturated operation: There was a saturating signal at $1565 \mathrm{~nm}$, with input and output power of $-3.5 \mathrm{dBm}$ and $19.7 \mathrm{dBm}$, respectively. The noise figure degradation at shorter wavelengths is due to the strong absorption in the first few centimeters of the doped fiber. It can be improved by using alternative cladding-pumping technology such as GTWave [11], or with a pre-amplifier.

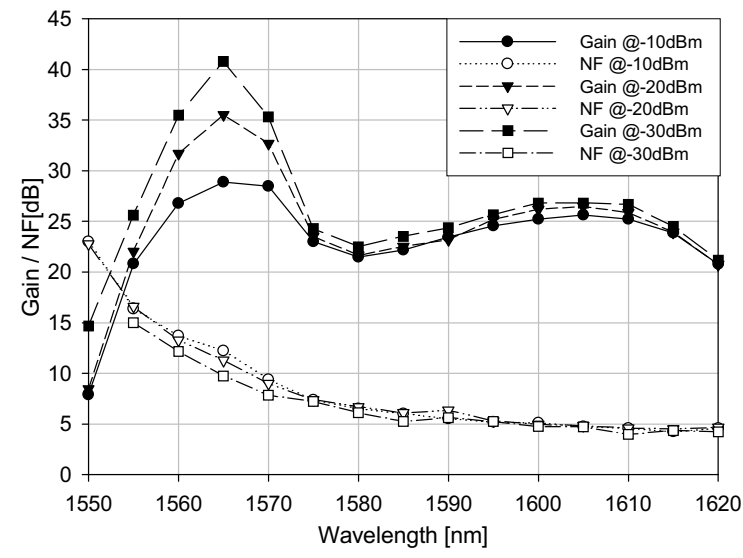

Figure 3: Single channel gain and noise figure.

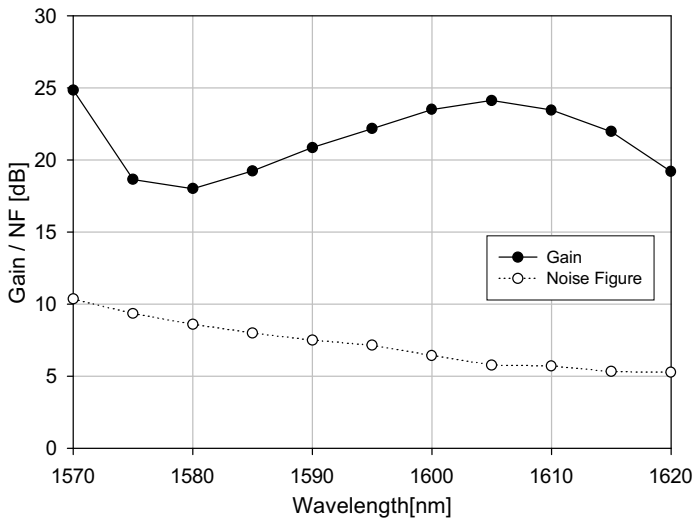

Figure 4: WDM gain and noise figure spectrum. 


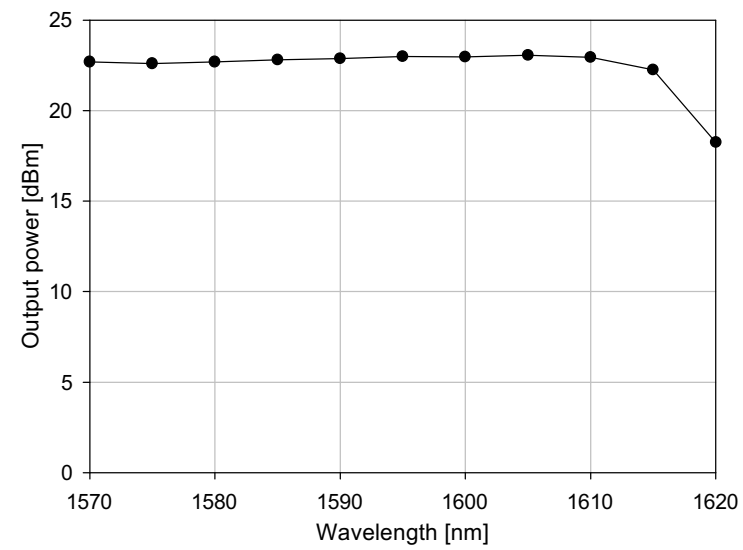

Figure 5: Output spectrum of a commercial amplifier cascaded with the EYDF amplifier.

The input power of the EYDF is $+13 \mathrm{dBm}$.

Even under strong input power $(+13 \mathrm{dBm})$, realized by using a commercial L-band EDFA as a preamplifier, the EYDFA shows a $10 \mathrm{~dB}$ gain and has a saturated output power of $23 \mathrm{dBm}$ (Fig. 5). The bandwidth is reduced because of the bandwidth limit of the pre-amplifier - it was not possible to operate beyond $1570 \mathrm{~nm}$. Signal-ESA may be a factor at long wavelengths.

\section{Conclusion}

In this paper, we presented a short, simple and low-cost, cladding-pumped phosphosilicate EYDFA. A 5 m long piece of fiber with $3800 \mathrm{ppm}$ Er (wt) provided over $20 \mathrm{~dB}$ of gain from 1553 to $1620 \mathrm{~nm}$ in a double-passed configuration, with up to $23 \mathrm{dBm}$ of saturated output power. This combination of performance and cost appears exceptionally attractive.

\section{References}

[1] J. F. Massicot, J. R. Armitage et al., "High gain, broadband, 1.6 $\mu \mathrm{m} \mathrm{Er}^{3+}$ doped silica fibre amplifier", Electron. Lett., 26, pp1645-1646, (1990).

[2] N. Sugimoto, K. Ochiai et al., "Highly efficient and short length Lanthanun co-doped $\mathrm{Bi}_{2} \mathrm{O}_{3}$-based EDF for extended L-band amplification", OAA'02, post deadline paper 5-1.

[3] K. Aiso, Y. Tashiro et al., "Erbium Lanthanun co-doped fiber for L-band amplifier with high efficiency, low non-linearity and low NF", OFC'01, vol.2, TuA6-T1-3.

[4] G. G. Vienne et al., "Fabrication and Characterization of Yb3+ : Er3+ Phosphosilicate Fibers for Lasers", $J$. Lightwave Technol., 16, pp 1990, (1998).

[5] J. E. Townsend, et al., "Yb ${ }^{3+}$ sensitised $\mathrm{Er}^{3+}$ doped silica optical fibre with ultrahigh transfer efficiency and gain", Electron. Lett., vol. 27, pp. 1958-1959, (1991).

[6] J. D. Minelly,et al., "Diode-array pumping of $\mathrm{Er}^{3+} / \mathrm{Yb}^{3+}$ co-doped fiber lasers and amplifiers", IEEE Photonics Technol. Lett., 5, pp. 301-303, (1993).

[7] M. Söderlund, S. Tammela, et al., "Amplified spontaneous emission in cladding-pumped L-band erbium-doped fiber amplifiers", IEEE Photonics Technol. Lett. 13, (2001).

[8] J. Nilsson, S. Y. Sun, S. T. Hwang, J. M. Kim, and S. J. Kim, "Long-wavelength erbium-doped fiber amplifier gain enhancement by ASE end-reflector", IEEE Photonics Technol. Lett., 10, 1551-1553 (1998).

[9] F. Di Pasquale, G. Grasso, et al., " $23 \mathrm{dBm}$ output power Er/Yb co-doped fiber amplifier for WDM signals in the 1575 - 1605 nm wavelength region" OFC/IOOC'99. Tech. Dig., 1999, post-deadline paper WA2-1.

[10] M. Kakui, S. Ishikawa, "Long-wavelength-band optical amplifiers employing silica-based erbium doped fibers designed for wavelength division multeplexing systems and networks", IECE Trans. Electron., vol. E83-C, 6(2000). [11] C. Codemard, K. Ylä-Jarkko, et al., "Low noise, Intelligent cladding pumped L-band EDFA", ECOC'02, postdeadline paper 1.6 